\title{
Sensitivity of normalized difference vegetation index (NDVI) to land surface temperature, soil moisture and precipitation over district Gautam Buddh Nagar, UP, India
}

\author{
Manish Sharma ${ }^{1} \cdot$ Pargin Bangotra $^{1} \cdot$ Alok Sagar Gautam $^{2} \cdot$ Sneha Gautam ${ }^{3}$ \\ Accepted: 19 July 2021 / Published online: 25 July 2021 \\ (C) The Author(s), under exclusive licence to Springer-Verlag GmbH Germany, part of Springer Nature 2021
}

\begin{abstract}
This study examines the trends in MODIS/TERRA derived Normalized Difference Vegetation Index (NDVI) and its correlation with Land Surface Temperature (LST), Soil Moisture (SM), and precipitation over Gautam Buddh Nagar (India), during the period 2005-2018. The region have a sub-humid and quite moderate climate, scattered into cultivable land, forest and fast growing urbanization zone, making it suitable for monitoring vegetation trends and its accompanying factors. The NDVI-derived vegetation growth patterns over the study region of District Gautam Buddh Nagar, illustrate vigorous seasonal cycles, and interannual variations. The correlation between NDVI, and LST $(-0.45)$ was observed to be higher than the correlation of NDVI with SM $(r=0.43)$, and precipitation $(r=0.341)$, suggesting NDVI as more sensitive to LST as compare to SM, and precipitation, while SM shows the worthy positive correlation $(r=0.63)$ with the precipitation. On a seasonal basis, NDVI shows high values during winter $(0.45 \pm 0.02)$ followed by monsoon $(0.44 \pm 0.04)$, post-monsoon $(0.41 \pm 0.02)$, and pre-monsoon $(0.37 \pm 0.04)$. This study also aims to determine the phase wise status of NDVI and associated parameters.
\end{abstract}

Keywords Normalized Difference Vegetation Index · Precipitation · Land Surface Temperature · Soil Moisture · Remote Sensing · Gautam Buddh Nagar

\section{Introduction}

The regional monsoon system, atmospheric variability, air trajectory, and Spatio-temporal distribution of emission sources exhibit a remarkable importance for seasonal. and inter-annual inconsistency over the Indo-Gangetic plain

Pargin Bangotra

pargin.bangotra@sharda.ac.in

$\bowtie$ Alok Sagar Gautam phyalok@gmail.com

$\triangle$ Sneha Gautam gautamsneha@gmail.com; snehagautam@karunya.edu

1 Atmospheric Research Laboratory, School of Basic Sciences and Research, Sharda University, Greater Noida, India

2 Department of Physics, Hemvati Nandan Bahuguna Garhwal University, Uttarakhand, India

3 Karunya Institute of Technology and Sciences, Tamil Nadu, Coimbatore, India
(IGP) of the Northern region, (India) considered to be most densely populated as well as polluted regions of the world (Ramachandran et al. 2008; Abish and Mohanakumar 2011; Henriksson et al. 2011; Kaskaoutis et al. 2011; Gautam et al. 2011). The meteorological parameters especially surface air temperature and relative humidity have ability to alter the deposition process of particulate matters and the migration of other weighty atmospheric pollutants (Ambade et al. 2021; Gautam et al. 2021; Gautam and Brema, 2020). Numerous researchers across the globe, proved the correlation and impact of environmental pollution to human health and distinct diseases (Gollakota et al. 2021; Cohen et al. 2005; Bangotra et al. 2021, 2019). Some recent studies showed the impact of lockdown (COVID 19 phase) on the transportation and concentration of particulate matter (PM1.0, PM2.5 and PM10) and other related hazardous pollutants (Gautam et al. 2020a; Gautam, 2020; Wang et al. 2020; Sharma et al. 2020). Consequently, the decline in air quality index affects the ecosystems and urbanization that may have serious 
climatic implications. Remote sensing has changed the manner in which the land assets are seen, utilized, and oversaw. The equivalent applies toward how NDVI is ensnared with vegetation heath, and status. There is no uncertainty that NDVI will keep on being a rule vegetation list, however the compelling utilization of NDVI relies upon the nature of multispectral information and the understanding of NDVI esteems (Huang et al. 2020). The study conducted by Dagnachew et al. (2019) broke down the spatial and fleeting NDVI varieties in the yearly, month-to-month, and four unique seasons in the Gojeb River Catchment and their reaction to climatic variables (precipitation) from 1982 to 2015. Temperature and precipitation are firmly connected with the vegetation amount and quality in a spot. Regular fluctuation in environment alongside human cooperations has significant effect (Sha et al. 2020).

The long-term knowledge of vegetation dynamics and its associate factors play a substantial role in demonstrating the climate change pattern and monsoon variability. NDVI has been recognized as one of the important parameter to study the seasonal vegetation cover and crop health (Sellers et al. 1986; Piao et al. 2004; Mabuchi et al. 2005; Kumar et al. 2013). Solar radiation, LST, SM and precipitation have a great impact on vegetation growth pattern (Kumar et al. 2013). NDVI represents the greenness on the land surface, and confirms the density of vegetation (Choubin et al. 2017; Hosseini et al. 2018).

NDVI $=\frac{\text { NearIR }- \text { Red }}{\text { NearIR }+ \text { Red }}$

Here IR represents the infrared $(0.841-0.876 \mu \mathrm{m})$, while, Red denotes the band of Red color $(0.620-0.670 \mu \mathrm{m})$. The value of NDVI varies from -1 to 1 as shown in Eq. 1 (Tucker et al. 1979). The negative value of NDVI represents water coverage, the values approaching to zero ( -0.1 to 0.1$)$ are associated to barren land of rock, sand, and snow, while $0.2-0.4$ characterizes the plant and vegetation cover. The deep understanding of NDVI and its association with climatic variables is an imperative and attractive aspiration for predicting outlook vegetation expansion, and their responses to climatic change. Satellite derived vegetation index has been also identified as significant, to explore the response of vegetation on climate change (Tucker, 1979; Piao et al. 2011; Zhang et al. 2013). Eastman et al. (2013) quantified the long term regional vegetation dynamics with the help of third-generation Global Inventory Modelling and Mapping Studies (GIMMS) derived from the Advanced Very HighResolution Radiometer (AVHRR) sensors. Various techniques based on artificial neural network, simulation, discrete wavelet transform dependent satellite image contrast enhancement, and singular value decomposition were used to estimate the dynamical characteristics of NDVI (Demirel et al. 2010; Yamaguchi et al. 2010; Bhandaria et al. 2012). Mallick et al. (2012) used the Landsat-7 ETM data to study the LST, an excellent indicator of the earth's energy balance. Further, Senanayak et al. (2013) validated the association of NDVI and LST using inverse proportion to NDVI i.e., Environmental Criticality Index (ECI) and the same was also confirmed by Fricke et al. (2014). On a seasonal basis, Singh et al. (2014) used Landsat Thematic Mapper (TM) satellite images of Delhi and described the dissemination, and fluctuations in surface temperature.

The long-term analysis of precipitation has great importance due to its critical consequences on the regional climate, annual crop, and local economy (Kumar et al. 1992; Basistha et al. 2009; Duhan et al. 2013). The similar characteristics have been increasingly examined over different regions of India by revealing the dynamical nature of vegetation and their dependence on rainfall, as well as on temperature (Gautam et al. 2020b; Kundu and Dutta 2011; Dutta et al. 2015; Sahoo et al. 2015; Kundu et al. 2017). Gao et al. (2014) also studied the significance of SM on the growth of vegetation by considering its role as prime interface between surface and atmosphere.

The present attempt is the foremost study to examine the NDVI trends for fourteen years of satellite data and its sensitivity to LST, SM and Precipitation on a monthly and seasonal basis over District Gautam Buddh Nagar. Robust statistical tools have also been applied to validate the important consequence of dynamical characteristics of NDVI.

\section{Study location and data sets}

\subsection{Study location}

Gautam Buddh Nagar (GBN) district (Fig. 1), a part of Ganga-Yamuna Doab approximately River Yamuna was formed in year 1997, by merging different blocks as Noida, Greater Noida, Jewar and Sikandrabad etc. The district is enclosed by Ghaziabad and Delhi in Northside, by Aligarh in South, in the East by Bulandshahar, and West side by border of Haryana State. The GBN $\left(1265 \mathrm{~km}^{2}\right)$ is basically a sub-humid, and quite moderate climatic zone. Due to evolving urbanization and industrialization this zone severely affected by the high pollution level. The soil quality of this region varies from pure soil to hard clays. The utilization pattern of the total area $(125,422 \mathrm{ha})$ of the district is primarily scattered into net sown area (65,164 ha), forest (2003 ha), barren cultivable waste (2047 ha), current unplanted land (16,111 ha), other unplanted land (6145 ha), land put to non-agriculture use (33,694 ha) and grasslands (506 ha). 
Fig. 1 Location map of District Gautam Buddh Nagar (bounding box: East 77.41, South 28.26, West 77.64, and North 28.62)

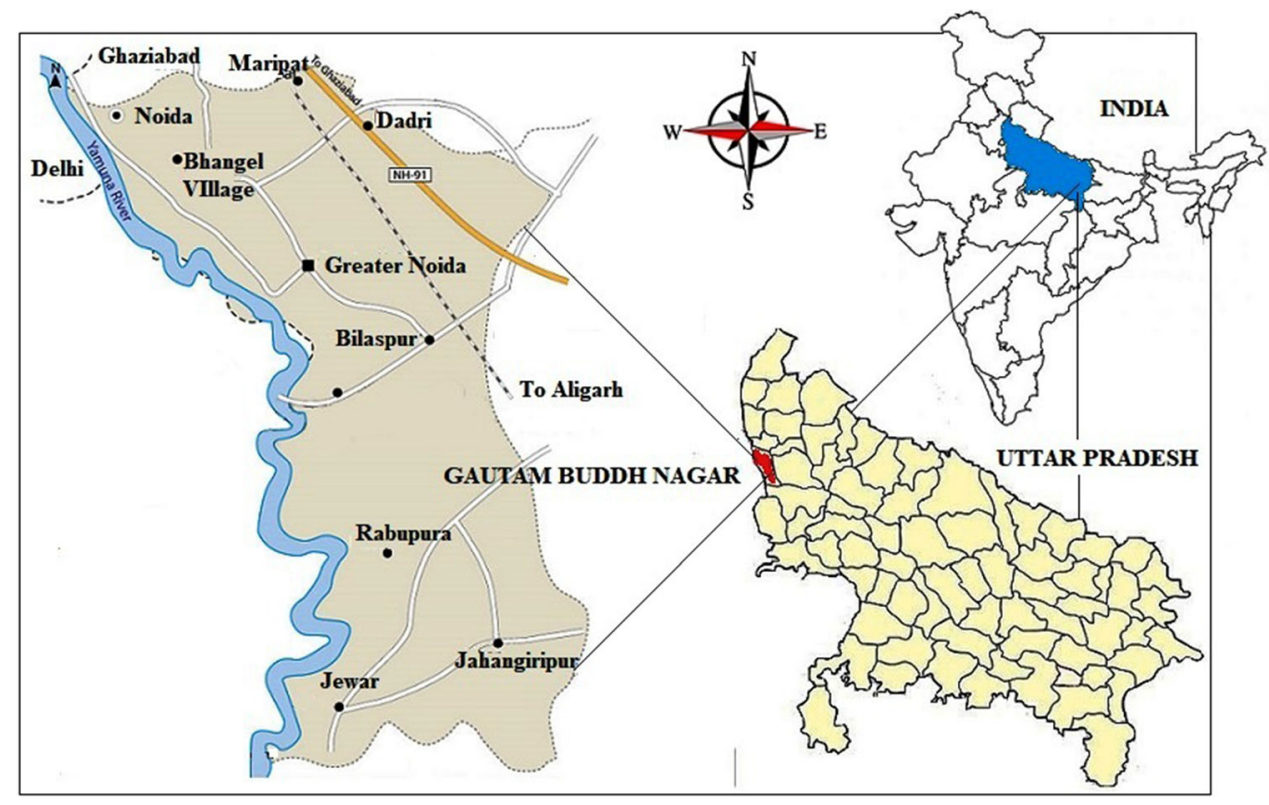

\subsection{Data Sets and statistical techniques}

Fourteen years monthly NASA supported Giovanni data of NDVI and associated meteorological parameters were used to see the vegetation pattern over GBN district (Table 1). Karl Pearson's coefficient of correlation " $r$ " (Eq. 2), kurtosis $(\mathrm{K})$ skewness $(\mathrm{Sk})$, inter-quartile range (IQR), and trend analysis were also used to analyze the dynamical variability of NDVI and its interrelationship with precipitation, LST and SM.

$r=\frac{\sum\left(X_{i}-\bar{X}\right)\left(Y_{i}-\bar{Y}\right)}{\sqrt{\sum\left(X_{i}-\bar{X}\right)^{2}\left(Y_{i}-\bar{Y}\right)^{2}}}$

where $\mathrm{X}$ and $\mathrm{Y}$ are variables. The Secular or long term trend analysis was used to observe the effect of trend whether it happens to be a growth factor or a decline factor. In view of this, the percent change in NDVI for the two periods i.e. 2005-2011 $\left(Z_{1}\right)$ and 2012-2018 $\left(Z_{2}\right)$ were determined using Eq. (3).

$$
\Delta G R=\frac{Z_{1}-Z_{2}}{Z_{1}} \mathrm{X} 100
$$

\section{Result and discussion}

\subsection{Estimating of vegetation dynamics}

The linear trend was estimated for NDVI, LST, SM, and precipitation for the period of 2005-2018 (Fig. 2a-d). The NDVI over the GBN region was found to be from 0.18 to 0.66 with average of 0.42 (Fig. 2a). The maximum and minimum monthly mean NDVI was observed in February 2005 (winter month) and May 2010 (pre-monsoon month), respectively. The trend of NDVI shows minor distribution of vegetation growth around its mean value by giving the standard deviation and variance as 0.13 and 0.02 , respectively. A higher annual mean NDVI (0.44) with LST $\left(32.37{ }^{\circ} \mathrm{C}\right)$ is observed in the 2006 , where relatively lower NDVI (0.40) during 2009, 2010, and 2014 with LST

Table 1 Details of the selected satellite/platforms, data source and data resolution

\begin{tabular}{llr}
\hline Data set & Data Source & Resolution \\
\hline (NDVI) MOD13C2: MODIS/Terra Vegetation Indices Monthly L3 Global & Giovanni, Goddard Earth Sciences & $0.05^{\circ} \times 0.05^{\circ}$ \\
(LST): MYD11C:MODIS/Aqua Land Surface Temperature Monthly L3 Global & Giovanni, Goddard Earth Sciences & $0.05^{\circ} \times 0.05^{\circ}$ \\
(Precipitation):TRMM_3B42RT_Daily.7: Precipitation, L3 & https://disc.gsfc.nasa.gov/datasets/ & TRMM_3B42_7 \\
& Giovanni, Goddard Earth Sciences & $0.25^{\circ} \times 0.25^{\circ}$ \\
(Soil moisture) Area-Averaged Soil moisture content (0-10 cm underground) & & $0.25^{\circ}$ \\
3-hourly. [GLDAS] &
\end{tabular}


Fig. 2 Linear trend of domainaveraged monthly-mean a NDVI b LST c Precipitation (d) SM from 2005 to 2018. (The red dotted line shows a trend line)

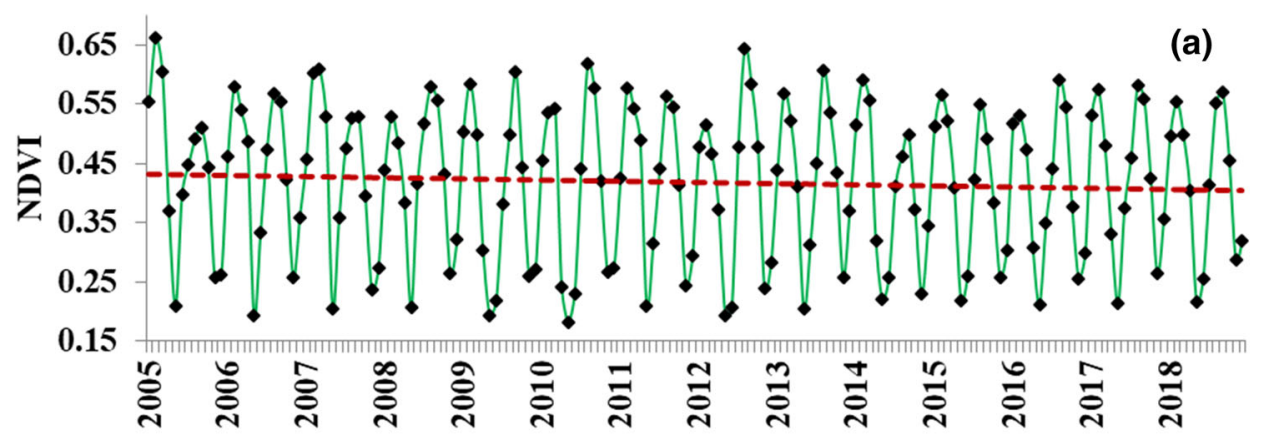

(b)

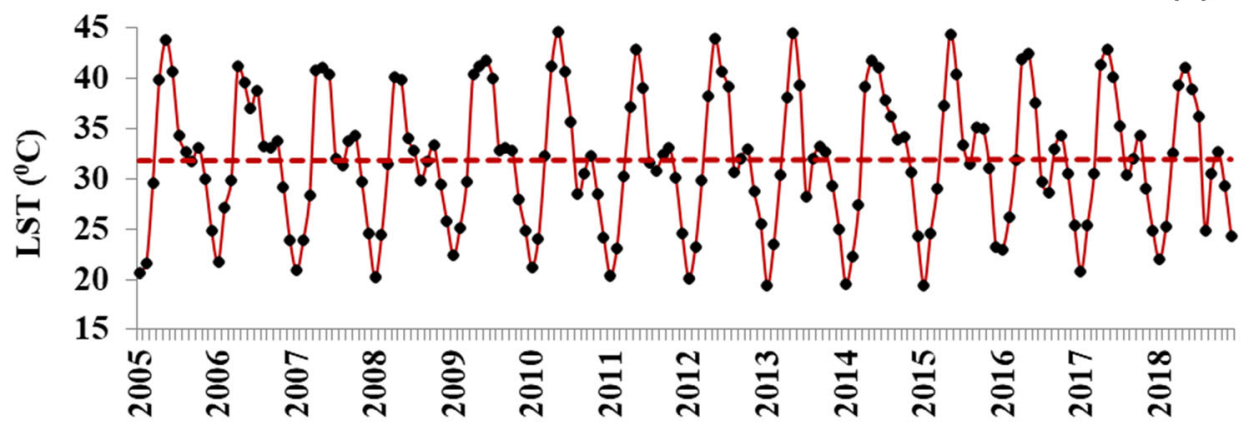

(c)

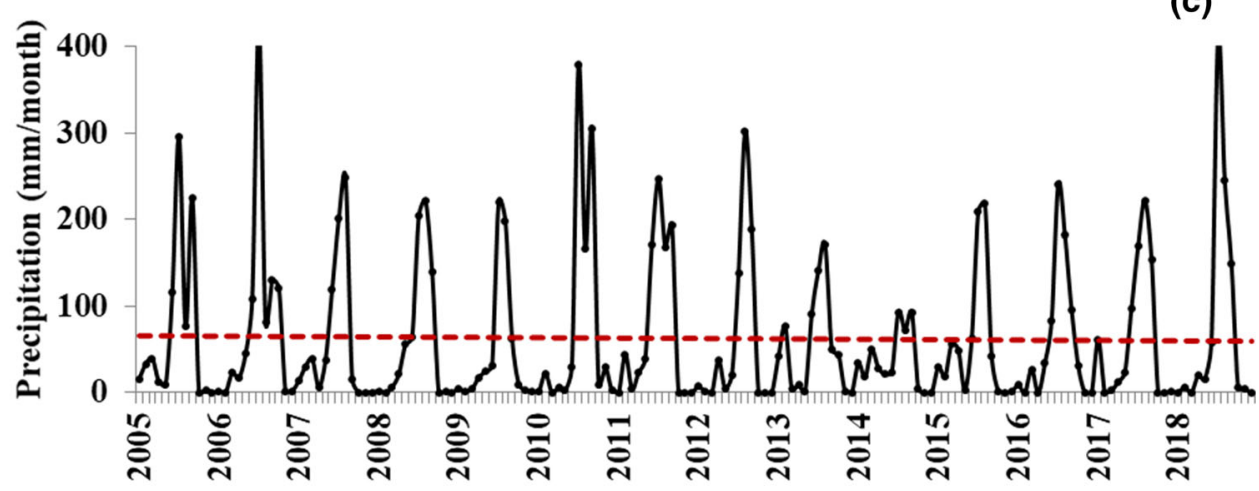

(d)

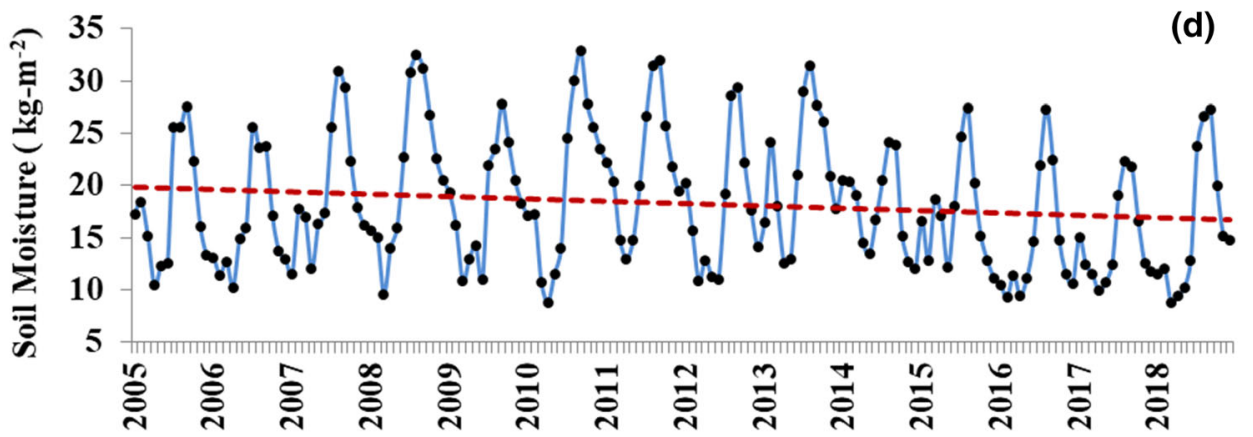

of $32.70,31.96$ and $32.36{ }^{\circ} \mathrm{C}$, respectively (Fig. 2b), declaring the evidence of declining trends of vegetation growth. The high NDVI during 2006 indicates a more sustainable climate for photosynthesis, and low NDVI in further years of 2009, 2010, and 2014, and it may be due to any shattering event and associated human activities like urbanization, industrialization etc. The inter annual variation of NDVI (Fig. 2a) and SM (Fig. 2d) is noteworthy due to their similar pattern, and strong association. The highest (0.44) and lowest (0.40) annual mean NDVI depicts a good 
association with the highest $\left(21.82 \mathrm{~kg} \mathrm{~m}^{-2}\right)$ and lowest $\left(14.55 \mathrm{~kg} \mathrm{~m}^{-2}\right)$ mean value of SM, and precipitation (high$79.57 \mathrm{~mm}$ per month, low-36.38 mm per month).

The variability of NDVI is interrelated with the production of crops and natural vegetation growth due to the dynamical characteristic of SM, and precipitation (Fig. 2c). Precipitation and SM are closely related to the growth of vegetation by the contribution of rainfall and LST. Karl Pearson's coefficient of correlation was estimated to understand the pattern of vegetation growth, and its associations to LST, SM, and Precipitation (Table 2). The NDVI shows the negative correlation $(r=0.45)$ with LST, whereas positive correlation with SM $(r=0.44)$ and precipitation $(r=0.34)$. The SM explains a positive correlation $(r=0.63)$ with the precipitation. The moderate-tostrong correlation between NDVI and associated meteorological parameters clearly reflects the dependence of climatic influence on vegetation growth.

\subsection{Periodic Investigation of NDVI}

The paired sample t-test method has been used to measure the performance of NDVI, LST, SM and Precipitation in two different phases by considering the period 2005-2011 as phase-1, and 2012-2018 as phase-II. In each phase, the seven years of monthly mean data was estimated (Table 3). The analysis shows the attained t-value of 0.82 with six degrees of freedom (DOF), and the statistical significance (2-tailed $p$-value) of paired t-test $(\operatorname{Pr}(|T|>|t|)$. The $p$-value of 0.44 indicates statistically significant difference (rejection of null hypothesis) which supports the finding of the percentage decrease of NDVI by $2.38 \%$ from phase-I.

In case of LST, phase-I and phase-II was observed a mean difference of -0.064 and a standard deviation of 0.703 , standard error of 0.26 at $95 \%$ confidence intervals (lower: 0.714 to upper: 0.585$)$. The $t(-0.243)$ and $p$ (0.816) values confirm the statistically significant difference between the two phases of LST (increase of $0.06{ }^{\circ} \mathrm{C}$ by $\left.0.2 \%\right)$. Further, the SM $(t$ value $=1.58$ and $p$ value $=0.16)$, and precipitation $(t$ value $=1.85$ and $p$ -

Table 2 Karl Pearson's coefficient of correlation of NDVI with LST, Precipitation, and SM based on the annual mean

\begin{tabular}{lllll}
\hline \multicolumn{2}{l}{ Pearson correlation } \\
\hline Parameters & NDVI & LST & Precipitation & Soil moisture \\
\hline NDVI & 1 & -0.45 & 0.34 & 0.44 \\
LST & -0.45 & 1 & 0.14 & -0.14 \\
Precipitation & 0.34 & 0.14 & 1 & 0.63 \\
SM & 0.44 & -0.14 & 0.63 & 1 \\
\hline
\end{tabular}

value $=0.114)$ also explain the statistical significance of accompanied test via demonstrating a decrease of 11.99 and $14.39 \%$ from phase-1, respectively. The complete paired $t$-test analysis validates the decrease in growth of vegetation. The decline in SM, and precipitation by 11.99 and $14.39 \%$ from phase-1, respectively validate the sensitivity of NDVI to SM, and precipitation over the District Gautam Buddh Nagar, UP, India.

\subsection{Seasonal characteristics of NDVI and its association with LST, SM and precipitation}

Different statistical tools were applied on data sets related to NDVI and its associated parameters (LST, SM, and Precipitation) to authenticate the accuracy of the findings.

\subsubsection{Statistical analysis}

The asymmetry distribution and tailless of seasonal NDVI, LST, SM and precipitation during 2005-2018 have been discussed to check the variation of normality and data spread (Table 4). All parameters exhibit fairly and moderately skewed values for winter, pre-monsoon, monsoon, and post-monsoon. The positive (1.29) and negative ( -1.01$)$ skewness was observed during winter and monsoon season, respectively, for precipitation suggest the highly skewed values, while the negative $(-0.07)$ skewness in pre-monsoon and positive (0.58) in the postmonsoon demonstrate the symmetrical distribution. The Kurtosis related to NDVI, LST, and SM show the shorter distribution with thinner tails as compared to normal distribution, which illustrates lack of outliers and platykurtic behavior. In case of precipitation, the high kurtosis ( $K=2.19$ and 3.19) exhibit heavy-tailed or abundance of outliers that demonstrate the leptokurtic behavior of distribution during winter and monsoon seasons, respectively. The Q-Q plots demonstrate approximately common distribution between the expected normal values, and the observed values of NDVI, LST, and SM. However, the precipitation shows the leptokurtic behavior with the heavy-tailed or profusion of outliers (Fig. 3).

The technique of grouping various observations has been applied to four dominant seasons and the results are summarized in box and whisker plot (Fig. 4). The results depict the seasonal spread of observed data i.e. winter, premonsoon, monsoon, and post-monsoon. The low interquartile range (IQR) of NDVI (0.03) during winter, and post-monsoon suggest high level of agreement (range: $0.07)$, whereas IQR $(0.05$ and 0.04$)$, and range $(0.13$ and 0.14 ) respectively, to pre-monsoon and monsoon attribute some inconsistency and highlights the significant influence of the LST, SM, and precipitation (Table 5). 
Table 3 Paired Samples

Statistics (a) and Paired Sample

Test results (b) of NDVI, LST,

SM, and Precipitation for two phases (phase-1: 2005-2011 and phase-2: 2011-2018)

\begin{tabular}{|c|c|c|c|c|c|c|c|c|c|}
\hline \multicolumn{10}{|c|}{ Paired Samples Statistics (a) } \\
\hline & & & Mean & $\mathrm{N}$ & \multicolumn{2}{|c|}{ Std. Deviation } & \multicolumn{3}{|c|}{ Std. Error Mean } \\
\hline \multirow[t]{2}{*}{ Pair 1} & \multicolumn{2}{|l|}{ NDVI1 } & 0.421 & 7 & \multicolumn{2}{|l|}{0.016} & \multicolumn{3}{|c|}{0.006} \\
\hline & \multicolumn{2}{|l|}{ NDVI2 } & 0.414 & 7 & \multicolumn{2}{|l|}{0.010} & \multicolumn{3}{|c|}{0.004} \\
\hline \multirow[t]{2}{*}{ Pair 2} & \multicolumn{2}{|l|}{ LST1 } & 31.864 & 7 & \multicolumn{2}{|l|}{0.567} & \multicolumn{3}{|c|}{0.214} \\
\hline & \multicolumn{2}{|l|}{ LST2 } & 31.929 & 7 & \multicolumn{2}{|l|}{0.407} & \multicolumn{3}{|c|}{0.153} \\
\hline \multirow[t]{2}{*}{ Pair 3} & \multicolumn{2}{|l|}{ SM1 } & 19.385 & 7 & \multicolumn{2}{|l|}{1.988} & \multicolumn{3}{|c|}{0.751} \\
\hline & \multicolumn{2}{|l|}{ SM2 } & 17.061 & 7 & \multicolumn{2}{|l|}{2.375} & \multicolumn{3}{|c|}{0.897} \\
\hline \multirow[t]{2}{*}{ Pair 4} & \multirow{2}{*}{\multicolumn{2}{|c|}{$\begin{array}{l}\text { PRECEPITATION } 1 \\
\text { PRECIPITATION } 2\end{array}$}} & 67.019 & 7 & \multicolumn{2}{|c|}{11.813} & \multicolumn{3}{|c|}{4.465} \\
\hline & & & 57.373 & 7 & \multicolumn{2}{|c|}{11.882} & \multicolumn{3}{|c|}{4.490} \\
\hline \multicolumn{10}{|c|}{ Paired Samples Test (b) } \\
\hline & & \multicolumn{5}{|c|}{ Paired Differences } & \multirow[t]{3}{*}{$\mathrm{t}$} & \multirow[t]{3}{*}{ df } & \multirow{3}{*}{$\begin{array}{l}\text { Sig. } \\
(2- \\
\text { tailed })\end{array}$} \\
\hline & & Mean & $\begin{array}{l}\text { Std. } \\
\text { Deviation }\end{array}$ & $\begin{array}{l}\text { Std. } \\
\text { Error } \\
\text { Mean }\end{array}$ & $\begin{array}{l}95 \% \text { Con } \\
\text { Interval } \\
\text { Differenc }\end{array}$ & $\begin{array}{l}\text { fidence } \\
\text { f the } \\
\text { e }\end{array}$ & & & \\
\hline & & & & & Lower & Upper & & & \\
\hline $\begin{array}{c}\text { Pair } \\
1\end{array}$ & NDVI1-NDVI2 & 0.006 & 0.022 & 0.008 & -0.013 & 0.027 & 0.823 & 6 & 0.442 \\
\hline $\begin{array}{c}\text { Pair } \\
2\end{array}$ & LST1-LST2 & -0.064 & 0.703 & 0.265 & -0.714 & 0.585 & -0.243 & 6 & 0.816 \\
\hline $\begin{array}{c}\text { Pair } \\
3\end{array}$ & SM1-SM2 & 2.324 & 3.890 & 1.470 & -1.273 & 5.922 & 1.581 & 6 & 0.165 \\
\hline $\begin{array}{c}\text { Pair } \\
4\end{array}$ & $\begin{array}{l}\text { PRECIPITATION1 } \\
- \\
\text { PRECIPITATION } \\
2\end{array}$ & 9.645 & 13.785 & 5.210 & -3.103 & 22.394 & 1.851 & 6 & 0.114 \\
\hline
\end{tabular}

Table 4 Seasonal variation of NDVI, LST, SM, and Precipitation during 2005-2018

\begin{tabular}{llrrrrrrrrrr}
\hline Parameter & & Min & Max & Mean & SD & Median & Range & Variance & IQR & \multicolumn{1}{c}{$S_{k}$} & \multicolumn{1}{c}{$K$} \\
\hline NDVI & Winter & 0.42 & 0.49 & 0.45 & 0.02 & 0.45 & 0.07 & 0.0005 & 0.03 & 0.25 & -0.88 \\
& Pre-monsoon & 0.32 & 0.45 & 0.37 & 0.04 & 0.37 & 0.13 & 0.0013 & 0.05 & 0.59 & -0.12 \\
& Monsoon & 0.37 & 0.50 & 0.44 & 0.04 & 0.44 & 0.14 & 0.0014 & 0.04 & -0.47 & 0.25 \\
& Post-monsoon & 0.37 & 0.44 & 0.41 & 0.02 & 0.41 & 0.07 & 0.0005 & 0.03 & -0.38 & -0.53 \\
Land Surface Temperature (LST) & Winter & 22.03 & 24.80 & 23.22 & 0.81 & 23.09 & 2.78 & 0.66 & 1.16 & 0.42 & -0.66 \\
& Pre-monsoon & 36.15 & 39.36 & 37.47 & 0.87 & 37.27 & 3.21 & 0.75 & 0.90 & 0.81 & 0.46 \\
& Monsoon & 31.98 & 38.35 & 35.01 & 2.00 & 35.01 & 6.38 & 4.01 & 2.78 & 0.20 & -0.71 \\
& Post-monsoon & 30.43 & 33.77 & 31.88 & 0.87 & 31.78 & 3.34 & 0.76 & 1.12 & 0.51 & 0.41 \\
Precipitation & Winter & 0.69 & 39.43 & 11.40 & 10.83 & 11.51 & 38.74 & 117.2 & 13.97 & 1.29 & $\mathbf{2 . 1 9}$ \\
& Pre-monsoon & 0.50 & 40.05 & 18.08 & 15.51 & 12.49 & 39.55 & 102.5 & 14.68 & -0.07 & -0.82 \\
& Monsoon & 4.95 & 40.79 & 16.02 & 9.99 & 13.47 & 35.84 & 1609.5 & 35.74 & -1.01 & $\mathbf{3 . 1 9}$ \\
Soil Moisture & Post-monsoon & 6.62 & 29.93 & 19.71 & 7.44 & 17.95 & 23.31 & 847.0 & 32.36 & 0.58 & 0.47 \\
& Winter & 10.09 & 20.67 & 15.87 & 3.11 & 16.51 & 10.59 & 9.67 & 4.64 & -0.25 & -0.83 \\
& Pre-monsoon & 9.47 & 15.95 & 12.79 & 2.07 & 12.62 & 6.48 & 4.27 & 3.46 & 0.02 & -1.13 \\
& Monsoon & 17.88 & 28.67 & 22.47 & 3.18 & 21.49 & 10.79 & 10.13 & 3.72 & 0.59 & -0.40 \\
& Post-monsoon & 16.06 & 28.73 & 21.77 & 4.26 & 22.51 & 12.68 & 18.18 & 7.23 & 0.01 & -1.33 \\
\hline
\end{tabular}



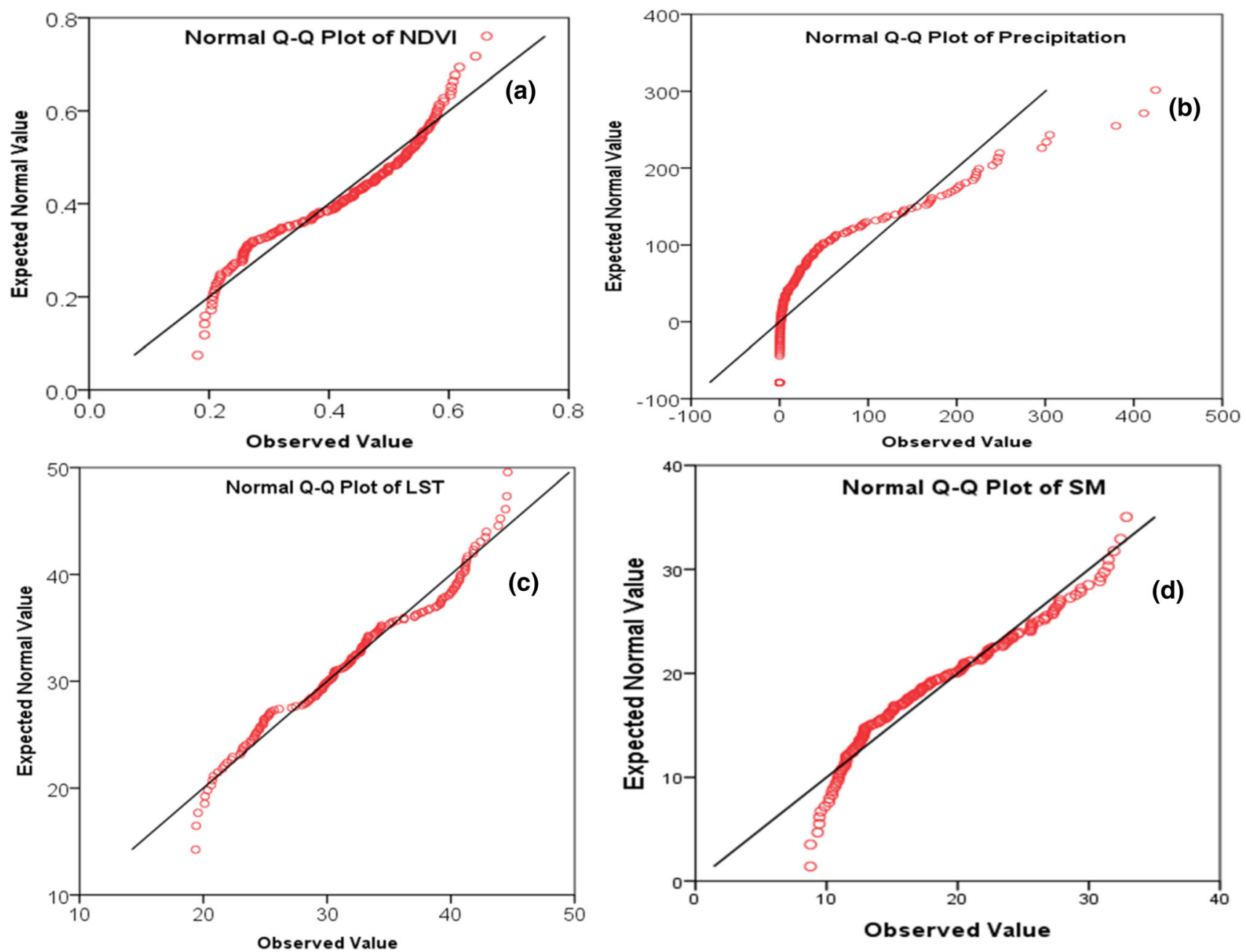

Fig. 3 Q-Q plots of a NDVI b Precipitation c Land Surface Temperature, and d Soil Moisture

The NDVI shows higher values during winter $(0.45 \pm 0.02)$, associated to elevated seasonal LST $(23.22 \pm 0.81)$ followed by monsoon $(0.44 \pm 0.04)$, postmonsoon (0.41 \pm 0.02$)$, and pre-monsoon $(0.37 \pm 0.04)$. The high value of NDVI during winter may be associated to the expansion in irrigation with surface water. However, in all seasons the standard deviation of NDVI was observed to be little bit large considering their differences in average NDVI that emphasis the need of long-term observations in order to understand the fluctuations caused by specific meteorological parameters. Box and whisker plots show the mean, median, and range of values related to LST, and precipitation (Fig. 4). Most of the outliers in LST were observed during pre-monsoon, whereas precipitation demonstrates large distributions of outliers during winter, monsoon, and post-monsoon.

Over district Gautam Buddh Nagar, the summer season mostly starts from April month and continues until the end of October, while the rainy season commences from June and withdrawal in the first week of October. The existing nine driest months i.e. September to April shows the lower values of precipitation as compared to rest of the wet season (Fig. 3). Maximum precipitation was observed during July and August (Fig. 5) and it may be strongly influenced by south-west monsoon winds coming from Indian Ocean by carrying moisture driven air masses. As annual vegetation growth is very sensitive to rainfall patterns, while the maximum outliers in October show the random consequences of uncertain rain and untimely conditions for condensation nuclei that further responsible for skewed distribution.

\subsection{Association among NDVI, LST, SM, and precipitation}

This section of the manuscript discusses the season-wise correlation coefficients among NDVI, LST, SM, and precipitation (Table 5). 

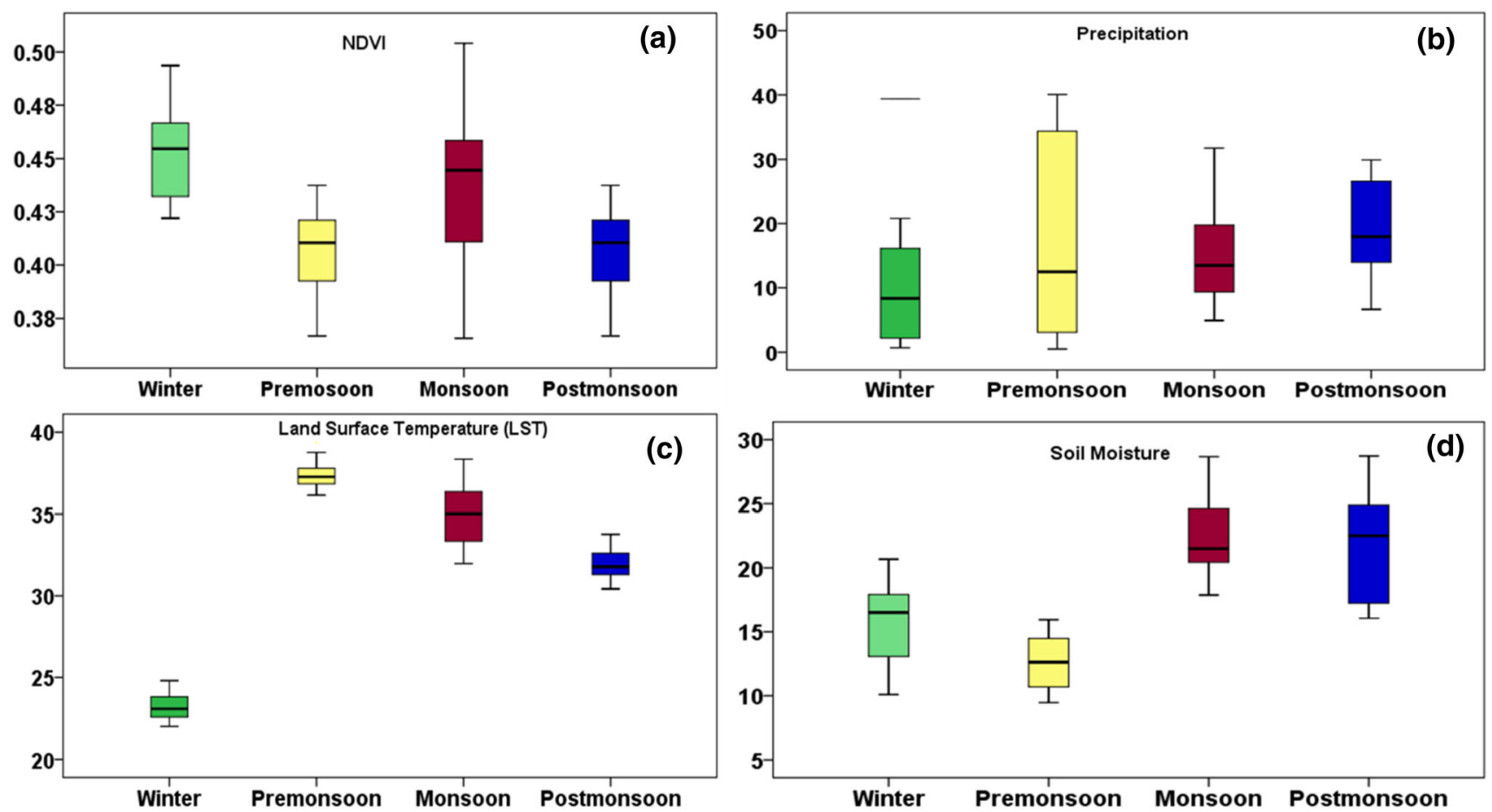

Fig. 4 Seasonal Box whisker plots of a NDVI b Precipitation $\mathbf{c}$ Land Surface Temperature d Soil Moisture

Table 5 Karl Pearson's coefficient of correlation of NDVI with LST, Precipitation and SM based on different seasons

\begin{tabular}{llllll}
\hline Parameter & & NDVI & LST & Precipitation & Soil moisture \\
\hline NDVI & Winter & 1 & -0.15 & 0.40 & -0.33 \\
& Pre-monsoon & 1 & -0.61 & 0.59 & 0.57 \\
& Monsoon & 1 & -0.65 & -0.28 & 0.47 \\
LST & Post-monsoon & 1 & -0.87 & 0.41 & 0.45 \\
& Winter & -0.16 & 1 & -0.59 & -0.60 \\
& Pre-monsoon & -0.61 & 1 & -0.71 & -0.75 \\
Precipitation & Monsoon & -0.65 & 1 & -0.46 & -0.63 \\
& Post-monsoon & -0.87 & 1 & -0.64 & -0.67 \\
& Winter & 0.40 & -0.59 & 1 & 0.35 \\
& Pre-monsoon & 0.47 & -0.71 & 1 & 0.65 \\
Soil Moisture & Monsoon & -0.28 & -0.46 & 1 & 0.1 \\
& Post-monsoon & 0.41 & -0.64 & 1 & 0.33 \\
& Winter & -0.33 & -0.59 & 0.35 & 1 \\
& Pre-monsoon & 0.57 & -0.75 & 0.65 & 1 \\
& Monsoon & 0.47 & -0.63 & 0.1 & 1 \\
\hline
\end{tabular}

\subsubsection{NDVI- LST}

A significant negative correlation between NDVI, and LST for pre-monsoon $(-0.61)$, Monsoon $(-0.65)$, and postmonsoon $(-0.87)$ seasons, respectively, was observed. Such high strong negative correlation in post-monsoon season may be persist due to high SM over the region (Fig. 4), which is in close agreement with the earlier reported observations (Hope et al. 1988). Although a weak
NDVI-LST correlation was observed during winter due to influencing effect of distinctive constraints and climatic conditions. For high altitude regions, a positive correlation between NDVI and LST was earlier reported, mainly due to increase of microbial activities, biochemical processes, and nitrogen availability (Dormann and Woodin 2002; Van Wijk et al. 2003). The microbial activities and biochemical processes play an important role in soil fertility that helps 

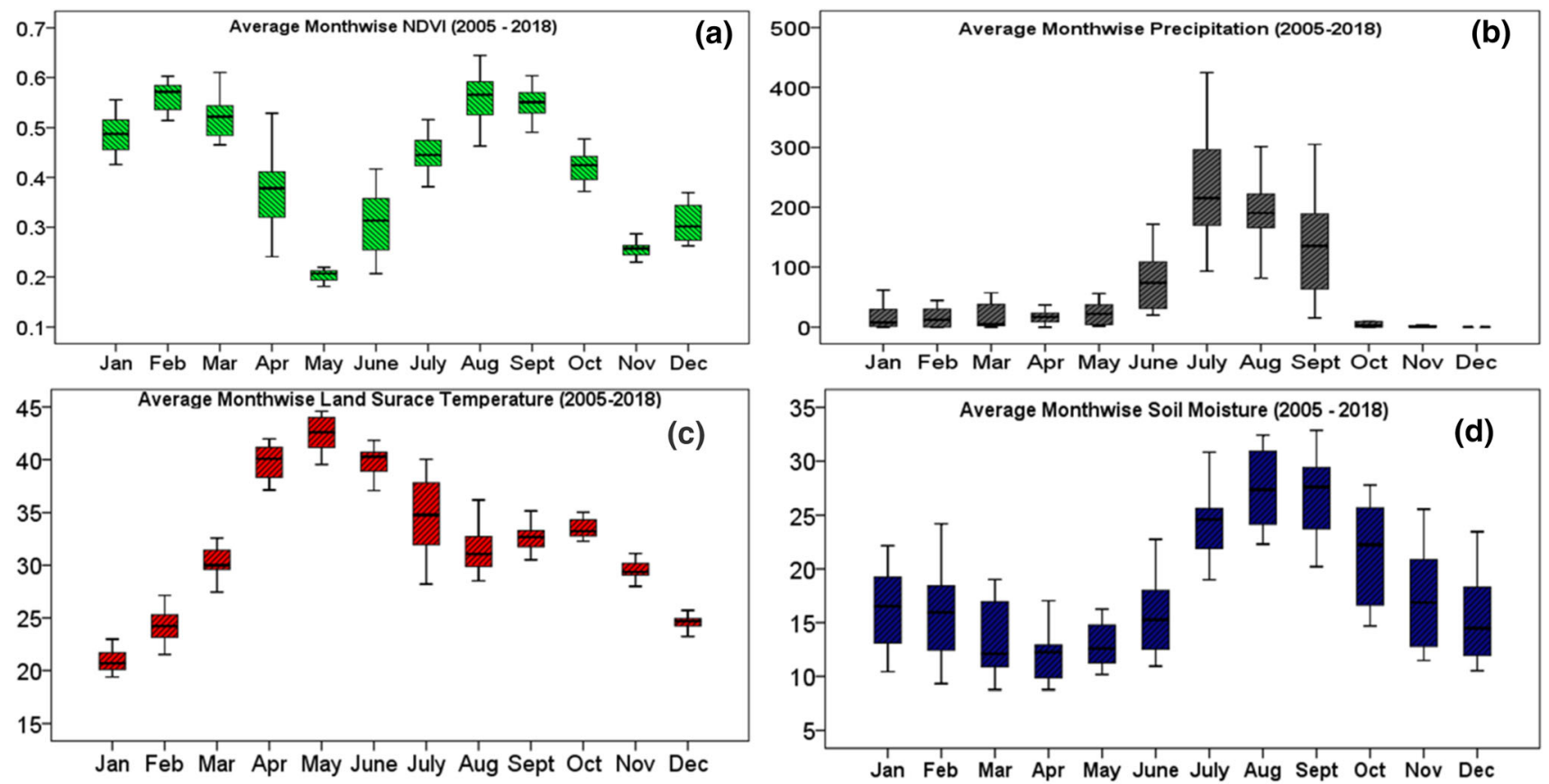

Fig. 5 Annual Box Whisker plots of a NDVI b Precipitation c Land Surface Temperature d Soil Moisture based on 12 months monthly mean

the growth of plant. In case of low altitude regions, the increase of LST causes the decline in plants growth. Additionally, GBN region has an elevation of $205 \mathrm{~m}$ as compared to $605 \mathrm{~m}$ of Shiwalik range of Himalayas, and a negative NDVI- LST correlation declares the effect of predominant solar radiations as compared to other biophysical variables.

\subsubsection{NDVI-precipitation}

A significant positive as well as moderate correlation between NDVI and precipitation during winter (0.40), premonsoon (0.59) and post-monsoon (0.41), However, a negative correlation (-0.28) was observed during Monsoon season (Table 4). In earlier studies, it was observed the decline in photosynthesis during extreme wet seasons due to less availability of solar radiation (Schultz and Halpert 1993). NDVI-precipitation correlation further rely on land cover (grassland, cropland, forests, and urban area), climatic conditions (temperature, rainfall, humidity, and soil moisture), and elevation of particular region, and many researcher reported negative as well as positive correlation based on region choice, and weather conditions (Wang et al. 2013).

\subsubsection{NDVI- SM}

SM plays a vital role in a life span of plants that affect evaporation rate (water from the soil) and evapotranspiration (water from leaves) of crops and plants (Xiong et al. 2003; Huang et al. 2017).

In present study, a negative correlation $(-0.33)$ was noticedbetweenNDVI, and precipitationforwinterseasonand positive for pre-monsoon (0.57), monsoon (0.47), and winter seasons (0.45). In spite of that, the higher values of NDVI were observed for winter, and monsoon seasons (Table 4) due to typical climatic conditions over Indian Subcontinent region (methodology section) as compared to other continents. It was found the maximumNDVIduring AugustandFebruary, which is in close agreement with the findings related to wet and rainy, seasons (Zhang and Schilling 2006).

During monsoon season, the higher values of SM, and moderate values of LST, while in winter season, lower LST, and moderate SM were observed. These both conditions are in favor of photosynthesis, consequently due to the presence of energy source; maximum sugar can be produced from available water and carbon dioxide that supplementary increases the plant's metabolism to achieve healthy NDVI. Conversely, the lowest average NDVI in May month of pre-monsoon season has been recorded due to higher LST and lower SM. These circumstances elevate the evaporation and evapotranspiration rate from Soil and plants leaves, respectively during pre-monsoon that leads to decline the growth of plants, and trees. Figure 4 and Table 5 reveals a negative correlation between SM and LST for all seasons, and together these both parameters decide the fate of plants growth that further affects the NDVI over different regions, and seasons across the globe (Zhang et al. 2018). 


\section{Conclusions}

The findings in the manuscript depict the normal. underdispersed, and lower tailed distribution of NDVI, LST, and SM except precipitation. The average NDVI (2005-2018) in the study region was assessed as 0.45 , which indicates healthy vegetation. Nevertheless, the maximum NDVI was observed during the transition phases of winter to premonsoon (February), and Monsoon to post-monsoon (August). LST and SM were found to be positively correlated with NDVI due to less solar energy, and moderate soil moisture accessibility. Such circumstances support the photosynthesis process that results an excellent growth of vegetation. The negative and positive correlation were observed between NDVI, and precipitation for different seasons due to the higher uncertainty of precipitation. It has been observed that the soil moisture (SM) is most noticeable feature and responsible for the evolution of vegetation. As the altitude, variation also plays a critical role, which need the supplementary investigated. The finding of paired $t$-test validates the decrease in vegetation by claiming the dynamical characteristic of NDVI. The deteriorating values of SM, and precipitation by 11.99 and $14.39 \%$ from the phase- 1 , respectively validate the sensitivity of NDVI to SM and precipitation over the District Gautam Buddh Nagar, UP, India.

Acknowledgements The authors are very thankful to NASA Giovanni team for providing the access of satellite data and to Sharda University, Greater Noida, Karunya Institute of Technology and Sciences Coimbatore, Tamil Nadu, India \& Hemvati Nandan Bahuguna Garhwal University, Uttarakhand, India for providing the necessary support to conduct the study.

Author Contributions: The idea of the manuscript was conceptualized by MS and PB. PB and MS carried out the statistical analysis and interpretation of the results. $\mathrm{PB}, \mathrm{MS}, \mathrm{AG}$ and $\mathrm{SG}$ performed graphical analysis and interpretation of statistics. PB, MS, AG and SG contributed in different section of the manuscript. All authors contributed extensively to discussion the work and reviewing the manuscript.

Funding Any type of financial research funding is not involve.

\section{Declarations}

Conflicts of interest The authors declare no competing financial and non-financial interests. The authors also declare that they have no conflict of interests.

\section{References}

Abish B, Mohanakumar K (2011) Biennial Variability in aerosol optical depth associated with QBO modulated tropical tropopause. Atmos Sci Lett 13:61-66

Ambade B, Sankar TK, Panicker AS, Gautam AS, Gautam S (2021) Characterization seasonal variation source apportionment and health risk assessment of black carbon over an urban region of East India. Urban Clim 38:100896. https://doi.org/10.1016/j. uclim.2021.100896

Bangotra P, Sharma M, Mehra R, Jakhu R, Singh A, Gautam AS, Gautam S (2021) A systematic study of uranium retention in human organs and quatification of radiological and chemical doses from uranium ingestion. Environ Technol Innov 21:101360

Bangotra P, Mehra R, Jakhu R, Pandit P, Prasad M (2019) Quantification of an alpha flux based radiological dose from seasonal exposure to ${ }^{222} \mathrm{Rn},{ }^{220} \mathrm{Rn}$ and their different EEC species. Sci Rep 9:2515

Bhandaria AK, Kumara A, Singh GK (2012) Feature Extraction using Normalized Difference Vegetation Index (NDVI): a Case Study of Jabalpur City. Procedia Technol 6:612-621

Basistha A, Arya DS, Goel NK (2009) Analysis of historical changes in rainfall in the Indian Himalayas. Int J Climatol 29(4):555-572

Choubin B, Solaimani K, Roshan MH, Malekian A (2017) Watershed classification by remote sensing indices: A fuzzy c-means clustering approach. J Mt Sci 14:2053-2063

Cohen AJ, Anderson HR, Ostra B, Pandey KD, Krzyznowski M, Gutschmidt NKK, Pope A, Romieu I, Samet RJM, Smith K (2005) The global burden of disease due to outdoor air pollution. J Toxicol Environ Health A 68:1-7

Duhan D, Pandey A (2013) Statistical analysis of long-term spatial and temporal trends of precipitation during 1901-2002 at Madhya Pradesh. India Atmos Res 122:136-149

Dormann CF, Woodin SJ (2002) Climate change in the Arctic: Using plant functional types in a meta-analysis of field experiments. Funct Ecol 16:4-17

Dutta D, Kundu A, Patel NR, Saha SK, Siddiqui AR (2015) Assessment of agricultural drought in Rajasthan (India) using remote sensing derived Vegetation Condition Index (VCI) and Standardized Precipitation Index (SPI). Egypt J Remote Sens Space Sci 18(1):53-63

Demirel H, Ozcinar C, Anbarjafari G (2010) Satellite image contrast enhancement using discrete wavelet transform and singular value decomposition. IEEE Geosci Remote Sens Lett 7(2):333-337

Eastman JR, Sangermano F, Machado EA, Rogan J, Anyamba A (2013) Global trends in seasonality of normalized difference vegetation index (NDVI), 1982-2011. Remote Sense 5:4799-4818

Fricke C, Pongrácz R, Dezső ZS, Bartholy J (2014) The role of vegetation in urban heat phenomenon in Budapest (in Hungarian). Légkör 59:150-153

Gautam S (2020) COVID-19: air pollution remains low as people stay at home. Air Qual Atmos Health 13:853-857

Gautam S, Brema J (2020) Spatio-temporal variation in the concentration of atmospheric particulate matter: a study in fourth largest urban agglomeration in India. Environ Technol Innov. https:// doi.org/10.1016/j.eti.2019.100546

Gautam S, Brema J, Dhasarathan R (2020b) Spatio-temporal estimates of solid waste disposal in an urban city of India: A remote sensing and GIS approach. Environ Technol Innov 18:100650. https://doi.org/10.1016/j.eti.2020.100650

Gautam S, Gautam AS, Singh K, James EJ, Brema J (2021) Investigations on the relationship among lightning, aerosol concentration, and meteorological parameters with specific reference to the wet and hot humid tropical zone of the southern parts of India. Environ Technol Innov. https://doi.org/10.1016/j. eti.2021.101414

Gautam R, Hsu NC, Tsay SC, Lau KM, Holben BN, Bell S, Smirnov A, Li C, Hansell R, Ji Q, Payra S, Aryal D, Kayastha R, Kim KM (2011) Accumulation of aerosols over the Indo-Gangetic plains and southern slopes of the Himalayas: distribution, properties 
and radiative effects during the 2009 pre-monsoon Season. Atmos Chem Phys 11:12841-12863

Gautam AS, Kumar S, Gautam S, Anand A, Kumar R, Joshi A, Bauddh K, Singh K (2020b) Pandemic induced lockdown as a boon to the environment: Trends in air pollution concentration across India. Asia-Pac J Atmos Sci. https://doi.org/10.1007/ s13143-021-00232-7

Gao SG, Zhu ZL, Liu SM, Jin R, Yang GC, Tan L (2014) Estimating the spatial distribution of soil moisture based on Bayesian maximum entropy method with auxiliary data from remote sensing. Int J Appl Earth Obs 32:54-66

Gollakota ARK, Gautam S, Santosh M, Sudan HA, Gandhi R, Sam Jebadurai V, Shu C-M (2021) Bioaerosols: Characterization pathways sampling strategies and challenges to geo-environment and health. Gondwana Res 99:178-203. https://doi.org/10.1016/ j.gr.2021.07.003

Henriksson SV, Laaksonen A, Kerminen VM, Räisänen P, Järvinen H, Sundström AM, de Leeuw G (2011) Spatial distributions and seasonal cycles of aerosols in India and China seen in global climate-aerosol model. Atmos Chem Phys 11:7975-7990

Hope AS (1988) Estimation of wheat canopy resistance using combined remotely sensed spectral reflectance and thermal observations. Remote Sens Environ 24:369-383

Huang S, Huang Q, Leng G, Zhao M, Meng E (2017) Variations in annual water-energy balance and their correlations with vegetation and soil moisture dynamics: A case study in the Wei River Basin. China J Hydrol 54:515-525

Huang S, Tang L, Hupy JP, Wang Y, Shao G (2020) A commentary review on the use of normalized difference vegetation index (NDVI) in the era of popular remote sensing. J for Res 32:1-6

Hosseini FS, Choubin B, Solaimanim K, Cerda A, Kavian A (2018) Spatial prediction of soil erosion susceptibility using a fuzzy analytical network process: application of the fuzzy decision making trial and evaluation laboratory approach. Land Degrad Dev 29(9):3092-3103

Kaskaoutis DG, Kharol SK, Sinha PR, Singh RP, Kambezidis HD, Sharma AR, Badarinath KVS (2011) Extremely large anthropogenic-aerosol contribution to total aerosol load over the Bay of Bengal during winter season. Atmos Chem Phys 11:7097-7117

Kumar TVL, Kundeti K, Barbosa HA, Jyoti EP (2013) Studies on spatial pattern of NDVI over India and its relationship with rainfall, air temperature. Soil Moisture Adequacy ENSO Geofizika 30(1):1-18

Kundu A, Dutta D (2011) Monitoring desertification risk through climate change and human interference using remote sensing and GIS techniques. I J Geomat Geosci 2(1):21-33

Kundu A, Patel NR, Saha SK, Dutta D (2017) Desertification in western Rajasthan (India): A assessment using remote sensing derived rain-use efficiency and residual trend methods. Nat Hazard 86(1):297-313

Kumar KR, Pant GB, Parthasarathy B, Sontakke NA (1992) Spatial and sub seasonal patterns of the long-term trends of Indian summer monsoon rainfall. Int J Climatol 12(3):257-268

Mallick J, Singh CK, Shashtri S, Rahman A, Mukherjee S (2012) Land surface emissivity retrieval based on moisture index from Landsat TM satellite data over heterogeneous surfaces of Delhi city. Int J Appl Earth Obs Geoinf 19:348-358

Mabuchi K, Sato Y, Kida H (2005) Climatic impact of vegetation change in the Asian Tropicalregion. Part I: case of the Northern Hemisphere summer. J Clim 18:410-428

Piao SL, Wang XH, Ciais P, Zhu B, Wang T, Liu J (2011) Changes in satellite-derived vegetation growth trend in temperate and boreal
Eurasia from 1982 to 2006. Global Change Bio 17(10):3228-3239

Piao S, Fang J, Wei J, Qinghua G, Jinhu K, Shu T (2004) Variation in a Satellite Based Vegetation Index in Relation to Climate in China. J Veg Sci 15:219-226

Ramachandran S, Cherian R (2008) Regional and seasonal variations in aerosol optical characteristics and their frequency distributions over India during 2001-2005. J Geophys Res 113:D08207

Sahoo RN, Dutta D, Khanna M, Kumar N, Bandyopadhyay SK (2015) Drought assessment in the Dhar and Mewat districts of India using meteorological hydrological and remote sensing derived indices. Nat Hazards 77(2):733-751

Schultz PA, Halpert MS (1993) Global correlation of temperature. NDVI Precipitation Adv Space Res 13(5):277-280

Sellers PJ, Mintz Y, Sud YC, Dalcher A (1986) A simple biosphere model (SIB) for use within general circulation models. J Atmos Sci 43:505-531

Senanayake IP, Welivitiya WDDP, Nadeeka PM (2013) Remote sensing based analysis of urban heat islands with vegetation cover using Landsat-7 ETM+ data. Urban Clim 5:19-35

Sha K, Srinivasa A, Dhanya M (2020) The study on variability of NDVI over Kerala using satellite observations. AIP Conference Proceedings. 228: 020013.

Sharma M, Bangotra P (2020) Lockdown impact on particulate matter and role of meteorological parameters in the transmission of Covid-19. Nature Environ Pollut Technol 19(4):1627-1636

Singh D, Buchunde PS, Singh RP, Nath A, Kumar S, Ghodpag RN (2014) Lightning and Convective Rain Study in Different Parts of India. Atmos Res 137:35-48

Tucker CJ (1979) Red and photographic infrared linear combinations for monitoring vegetation. Remote Sens Environ 8:127-150

Van Wijk MT, Williams M, Laundre JA, Shaver GR (2003) Inter annual variability of plant phenology in tussock tundra: Modelling interactions of plant productivity, plant phenology, snowmelt and soil thaw. Global Change Bio 9:743-758

Wang J, Rich PM, Price KP (2013) Temporal responses of NDVI to precipitation and temperature in the central Great Plains, USA. Int J Remote Sens 24(11):2345-2364

Wang P, Chen K, Zhu S, Wang P, Zhang H (2020) Severe air pollution events not avoided by reduced anthropogenic activities during COVID-19 outbreak. Resour Conserv Recycl 158:104814

Xiong S, Johansson ME, Hughes FMR, Hayes A, Richards K, Nilsson C (2003) Interactive effects of soil moisture, vegetation canopy, plant litter and seed addition on plant diversity in a Wetland Community. J Ecol 91(6):976-986

Yamaguchi T, Kishida K, Nunohiro E, Park JG, Mackin KJ, Matsushita KHK, Harada I (2010) Artificial neural network paddy-field classifier using spatiotemporal remote sensing data. Artif Life Robot 15(2):221-224

Zhang Y, Gao J, Liu L, Wang Z, Ding M, Yang X (2013) NDVIbased vegetation changes and their responses to climate change from 1982 to 2011: A case study in the Koshi River Basin in the middle Himalayas. Glob Planet Change 8:139-148

Zhang H, Chang J, Zhang L, Wang Y, Li Y, Wang X (2018) NDVI dynamic changes and their relationship with meteorological factors and soil moisture. Environ Earth Sci 77:582

Zhang YK, Schilling KE (2006) Effects of land cover on water table, soil moisture, evapotranspiration, and groundwater recharge: A Field observation and analyses. J Hydrol 319:328-338

Publisher's Note Springer Nature remains neutral with regard to jurisdictional claims in published maps and institutional affiliations. 